\title{
Erratum to: TDP-43 Proteinopathy and ALS: Insights into Disease Mechanisms and Therapeutic Targets
}

\author{
Emma L. Scotter • Han-Jou Chen • Christopher E. Shaw
}

Published online: 12 March 2015

(C) The American Society for Experimental NeuroTherapeutics, Inc. 2015

\section{ERRATUM TO: Neurotherapeutics}

DOI 10.1007/s13311-015-0338-x

This article published with citation errors. Reference citations are corrected below:

TDP-43 and TDP-43 Proteinopathy, Paragraph 1: "In the nucleus, TDP-43 plays a critical role in regulating RNA splicing, as well as modulating microRNA biogenesis $[8,9] . "$

Reference 9 should be: Kawahara Y, Mieda-Sato A. TDP-43 promotes microRNA biogenesis as a component of the Drosha and Dicer complexes. Proc Natl Acad Sci U S A. 2012;109(9):3347-52. doi:10.1073/pnas.1112427109.

TDP-43 and TDP-43 Proteinopathy, Paragraph 1: "In addition to TDP-43 RNA, TDP-43 regulates the splicing and stability of a large number of other transcripts [10, 12-15], and thus influences diverse cellular processes."

Reference 13 should be: Strong MJ, Volkening K, Hammond R, Yang W, Strong W, Leystra-Lantz C et al. TDP-43 is a human low molecular weight neurofilament (hNFL) mRNAbinding protein. Mol Cell Neurosci. 2007;35(2):320-327.

The online version of the original article can be found at http://dx.doi.org/ 10.1007/s13311-015-0338-x.

E. L. Scotter • H.-J. Chen • C. E. Shaw $(\square)$

Department of Basic and Clinical Neuroscience, Institute of

Psychiatry, Psychology and Neuroscience, King's College London, de Crespigny Park, London SE5 8AF, UK

e-mail: christopher.shaw@kcl.ac.uk

E. L. Scotter

Department of Pharmacology, University of Auckland,

Auckland, New Zealand

E. L. Scotter

Centre for Brain Research, University of Auckland, Auckland, New

Zealand
Reference 14 should be: Buratti E, Dork T, Zuccato E, Pagani F, Romano M, Baralle FE. Nuclear factor TDP-43 and SR proteins promote in vitro and in vivo CFTR exon 9 skipping. EMBO J. 2001;20(7):1774-84.

TDP-43 and TDP-43 Proteinopathy, Paragraph 2: "Although mostly nuclear, up to $\sim 30 \%$ of TDP-43 protein can be found in the cytoplasm [16], with nuclear efflux regulated by both activity and stress [17]."

Reference 17 should be: Wang IF, Wu LS, Chang HY, Shen CK. TDP-43, the signature protein of FTLD-U, is a neuronal activity-responsive factor. J Neurochem. 2008;105(3):797806. doi:10.1111/j.1471-4159.2007.05190.x.

Protein degradation gene mutations, Paragraph 1: “TDP43 proteostasis is normally maintained by the coordinated action of the UPS and autophagy, which is particularly important for clearing TDP-43 oligomers and aggregates [81-87]." This should be references 83-87

Protein degradation gene mutations, Paragraph 2: “Notably, VCP and p62 are required for the formation of "aggresomes" [84, 88, 89], which are large perinuclear inclusions decorated with ubiquitin, ubiquilin, and $\mathrm{p}$ 62."

Reference 84 should be: Pankiv S, Clausen TH, Lamark T, Brech A, Bruun JA, Outzen H et al. p62/SQSTM1 binds directly to Atg8/LC3 to facilitate degradation of ubiquitinated protein aggregates by autophagy. J Biol Chem. 2007;282(33):24131-45 (originally designated reference 79)

Protein degradation gene mutations, Paragraph 2: "The TDP- 43-positive aggregates that are the hallmark ALS pathology are likely aggresomes $[76,90] . "$

Reference 76 should be: Scotter EL, Vance C, Nishimura AL, et al. Differential roles of the ubiquitin proteasome system and autophagy in the clearance of soluble and aggregated TDP-43 species. J Cell Sci 2014;127: 1263-1278. (originally designated reference 83)

Protein degradation gene mutations, Paragraph 4: "Certainly, small molecule activators of the UPS or autophagy 
have been shown to promote TDP-43 clearance and/or mitigate toxicity in models based on TDP-43 overexpression [66, 77, 98, 99]."

Reference 77 should be: Caccamo A, Majumder S, Deng JJ, Bai Y, Thornton FB, Oddo S. Rapamycin rescues TDP-43 mislocalization and the associated low molecular mass neurofilament instability. J Biol Chem. 2009;284(40):27416-24. (originally designated reference 84 )

Environmental stress, Paragraph 1: "This idea was first proposed following observations of unexpectedly high disease incidence rates in certain "hotspots", such as the Kii peninsula of Japan and the island of Guam [36, 123, 124]."

Reference 36 should be: Brody JA, Stanhope JM, Kurland LT. Patterns of Amyotrophic Lateral Sclerosis and ParkinsonismDementia on Guam. Contemporary neurology series. 1975;12:45-70

Reference 124 should be: Waring SC, Esteban-Santillan C, Reed DM, Craig UK, Labarthe DR, Petersen RC et al. Incidence of amyotrophic lateral sclerosis and of the parkinsonism-dementia complex of Guam, 1950-1989. Neuroepidemiology. 2004;23(4):192-200. doi:10.1159/ 000078505.

Environmental stress, Paragraph 1: "While patients in these regions show an increased frequency of ALS-linked genes or genetic modifiers such as MAPT [125-128], these only partly account for the observed rates of disease."

Reference 126 should be: Poorkaj P, Tsuang D, Wijsman E, Steinbart E, Garruto RM, Craig UK et al. TAU as a susceptibility gene for amyotropic lateral sclerosis-parkinsonism dementia complex of Guam. Arch Neurol. 2001;58(11):1871-8. Reference 127 should be: Sundar PD, Yu CE, Sieh W, Steinbart E, Garruto RM, Oyanagi K et al. Two sites in the MAPT region confer genetic risk for Guam ALS/PDC and dementia. Hum Mol Genet. 2007;16(3):295-306. doi:10. 1093/hmg/ddl463.

Environmental stress, Paragraph 1: "Proposed environmental agents underlying the high incidence in these populations include dietary neurotoxins such as $\beta$ - methylamino-Lalanine $[129,130]$, or mineral deficiencies [75]."

Reference 129 should be: Spencer PS, Nunn PB, Hugon J, Ludolph A, Roy DN. Motorneurone disease on Guam: possible role of a food neurotoxin. Lancet. 1986;1(8487):965.

Reference 130 should be: Kisby GE, Ellison M, Spencer PS. Content of the neurotoxins cycasin (methylazoxymethanol beta-D-glucoside) and BMAA (beta-N-methylamino-L-alanine) in cycad flour prepared by Guam Chamorros. Neurology. 1992;42(7):1336-40.

Reference 75 should be: Garruto RM, Swyt C, Fiori CE, Yanagihara R, Gajdusek DC. Intraneuronal deposition of calcium and aluminium in amyotropic lateral sclerosis of Guam. Lancet. 1985;2(8468): 1353.

Environmental stress, Paragraph 2: "Exposure to electromagnetic fields $[87,114], \ldots .$.
Reference 87 should be: Hakansson N, Gustavsson P, Johansen C, Floderus B. Neurodegenerative diseases in welders and other workers exposed to high levels of magnetic fields. Epidemiology. 2003;14(4):420-6; discussion 7-8. doi:10.1097/01.EDE.0000078446. 76859.c9.

Reference 114 should be: Li CY, Sung FC. Association between occupational exposure to power frequency electromagnetic fields and amyotrophic lateral sclerosis: a review. American journal of industrial medicine. 2003;43(2):212-20. doi:10.1002/ajim.10148.

Environmental stress, Paragraph 2: “.....agricultural chemicals $[114,115,132] \ldots . "$

Reference 114 should be: Doi H, Kikuchi H, Murai H, Kawano Y, Shigeto H, Ohyagi Y et al. Motor neuron disorder simulating ALS induced by chronic inhalation of pyrethroid insecticides. Neurology. 2006;67(10):1894-5. doi:10.1212/01.wnl.0000244489. $65670.9 f$.

Reference 115 should be: Qureshi MM, Hayden D, Urbinelli L, Ferrante K, Newhall K, Myers D et al. Analysis of factors that modify susceptibility and rate of progression in amyotrophic lateral sclerosis (ALS). Amyotroph Lateral Scler. 2006;7(3):173-82. doi:10. 1080/14660820600640596.

Reference 132 should be: Furby A, Beauvais K, Kolev I, Rivain JG, Sebille V. Rural environment and risk factors of amyotrophic lateral sclerosis: a case-control study. J Neurol. 2010;257(5):792-8. doi:10.1007/s00415-009-5419-5.

Environmental stress, Paragraph 2: “...head injuries [113, 117],..”

Reference 113 should be: Chen H, Richard M, Sandler DP, Umbach DM, Kamel F. Head injury and amyotrophic lateral sclerosis. Am J Epidemiol. 2007;166(7):810-6. doi:10.1093/ aje/kwm153.

Reference 117 should be: Schmidt S, Kwee LC, Allen KD, Oddone EZ. Association of ALS with head injury, cigarette smoking and APOE genotypes. J Neurol Sci. 2010;291(12):22-9. doi:10.1016/j.jns.2010.01.011.

Environmental stress, Paragraph 2: “....and smoking [116, 119] may also increase susceptibility."

Reference 116 should be: Kamel F, Umbach DM, Munsat TL, Shefner JM, Sandler DP. Association of cigarette smoking with amyotrophic lateral sclerosis. Neuroepidemiology. 1999;18(4):194-202. doi:26211.

Reference 119 should be: Weisskopf MG, McCullough ML, Calle EE, Thun MJ, Cudkowicz M, Ascherio A. Prospective study of cigarette smoking and amyotrophic lateral sclerosis. Am J Epidemiol. 2004;160(1):26-33. doi:10.1093/aje/ kwh179.

Environmental stress, Paragraph 2: "Increased incidence of ALS has been reported in professional football players $[120,133,134] ; \ldots ”$ 
Reference 120 should be: Chio A, Benzi G, Dossena M, Mutani R, Mora G. Severely increased risk of amyotrophic lateral sclerosis among Italian professional football players. Brain. 2005;128(Pt 3):472-6. doi:10.1093/brain/awh373.

Reference 134 should be: Abel EL. Football increases the risk for Lou Gehrig's disease, amyotrophic lateral sclerosis. Perceptual and motor skills. 2007;104(3 Pt 2):1251-4. doi:10. 2466/pms.104.4.1251-1254.

Environmental stress, Paragraph 2: "however, this link has been disputed [135], and risk is not increased for other professional athletes [133]."

Reference 135 should be: Valenti M, Pontieri FE, Conti F, Altobelli E, Manzoni T, Frati L. Amyotrophic lateral sclerosis and sports: a case-control study. Eur J Neurol. 2005;12(3):223-5. doi:10.1111/j.1468-1331.2004.00978.x.

Environmental stress, Paragraph 3: “Osmotic stress [136], oxidative stress $[20,137,138]$, endoplasmic reticulum stress [66], and heat stress [138] can induce TDP-43 to redistribute from the nucleus to the cytoplasm and incorporate into stress granules."

Reference 66 should be: Walker AK, Soo KY, Sundaramoorthy V, Parakh S, Ma Y, Farg MA et al. ALSassociated TDP-43 induces endoplasmic reticulum stress, which drives cytoplasmic TDP-43 accumulation and stress granule formation. PLoS One. 2013;8(11):e81170. doi:10. 1371/journal.pone.0081170.

Environmental stress, Paragraph 3: "While the regulated aggregation of RBPs and RNA into stress granules is wholly reversible under normal conditions [99, 139]."

Reference 99 should be: Kedersha N, Cho MR, Li W, Yacono PW, Chen S, Gilks N et al. Dynamic shuttling of TIA-1 accompanies the recruitment of mRNA to mammalian stress granules. J Cell Biol. 2000;151(6):1257-68.

Fragmentation of TDP-43, Paragraph 1: "CTFs that correspond in size to those in ALS patient tissue may "seed" the formation of inclusions that are detergent-resistant and ubiquitinated [80]."

Reference 80 should be: Zhang YJ, Xu YF, Cook C, Gendron TF, Roettges P, Link CD et al. Aberrant cleavage of TDP-43 enhances aggregation and cellular toxicity. Proc Natl Acad Sci U S A. 2009;106(18):7607-12. (originally designated reference 87).

Misfolding, Aggregation, and Insolubility of TDP-43, Paragraph 1: “... and preventing visible TDP-43 aggregates from forming failed to reduce toxicity in a cellular model [159]."

Reference 159 should be: Liu R, Yang G, Nonaka T, Arai T, Jia W, Cynader MS. Reducing TDP-43 aggregation does not prevent its cytotoxicity. Acta neuropathologica communications. 2013;1(1):49. doi:10.1186/2051-5960-1-49.

Misfolding, Aggregation, and Insolubility of TDP-43, Paragraph 1: "It should be noted, however, that visible aggregates are only the endpoint of an aggregation pathway that includes a range of TDP-43 species from misfolded monomer to oligomer to mature aggregate [76]."

Reference 76 should be: Scotter EL, Vance C, Nishimura AL, et al. Differential roles of the ubiquitin proteasome system and autophagy in the clearance of soluble and aggregated TDP-43 species. J Cell Sci 2014;127: 1263-1278. (originally designated reference 83).

Misfolding, Aggregation, and Insolubility of TDP-43, Paragraph 2: "Subsequent to misfolding, the formation of oligomers and aggregates of TDP-43 in the cytoplasm may recruit native TDP-43 or its interactors [160]."

Reference 160 should be: Sephton CF, Cenik C, Kucukural A, Dammer EB, Cenik B, Han Y et al. Identification of neuronal RNA targets of TDP-43-containing ribonucleoprotein complexes. J Biol Chem. 2011;286(2):1204-15. doi:10.1074/jbc. M110.190884.

Misfolding, Aggregation, and Insolubility of TDP-43, Paragraph 3: "The chaperone system maintains proper protein folding during synthesis and thereafter, or delivers misfolded substrates for degradation [161]." Reference 161 should be: Hartl FU, Bracher A, HayerHartl M. Molecular chaperones in protein folding and proteostasis. Nature. 2011;475(7356):324-32. doi:10. 1038/nature10317.

Misfolding, Aggregation, and Insolubility of TDP-43, Paragraph 3: "Monomeric misfolded TDP-43 is likely handled by the UPS [76]."

Reference 76 should be: Scotter EL, Vance C, Nishimura AL, et al. Differential roles of the ubiquitin proteasome system and autophagy in the clearance of soluble and aggregated TDP-43 species. J Cell Sci 2014;127: 1263-1278. (originally designated reference 83).

Phosphorylation and Ubiquitination of TDP-43, Paragraph 3: "TDP-43 is modified with polyubiquitin chains that are predominantly K48- or K63-linked [7, 76, 173]."

Reference 76 should be: Scotter EL, Vance C, Nishimura AL, et al. Differential roles of the ubiquitin proteasome system and autophagy in the clearance of soluble and aggregated TDP-43 species. J Cell Sci 2014;127: 1263-1278. (originally designated reference 83).

The following references cited originally should be disregarded:

126. Smith Bradley N, Ticozzi N, Fallini C, et al. Exome-wide rare variant analysis identifies TUBA4A mutations associated with familial ALS. Neuron 2014;84:324-331.

127. Smith BN, Vance C, Scotter EL, et al. Novel mutations support a role for Profilin1 in the pathogenesis of ALS. Neurobiol Aging 2014 Oct 31 [Epub ahead of print]. 
129. Jansson D, Rustenhoven J, Feng S, et al. A role for human brain pericytes in neuroinflammation. J Neuroinflammation 2014;11:104.

130. Synofzik M, Born C, Rominger A, et al. Targeted highthroughput sequencing identifies a TARDBP mutation as a cause of early-onset FTD without motor neuron disease. Neurobiol Aging 2014;35:1212 e1-5.

132. Mizielinska S, Lashley T, Norona FE, et al. C9orf72 frontotemporal lobar degeneration is characterised by frequent neuronal sense and antisense RNA foci. Acta Neuropathol 2013;126:845-857.

135. Polling S, Mok YF, Ramdzan YM, et al. Misfolded polyglutamine, polyalanine, and superoxide dismutase 1 aggregate via distinct pathways in the cell. J Biol Chem 2014;289:6669-6680.

160. Tsuiji H, Iguchi Y, Furuya A, et al. Spliceosome integrity is defective in the motor neuron diseases ALS and SMA. EMBO Mol Med 2013;5:221-234. 